\title{
Contested multilateralism as credible signaling: how strategic inconsistency can induce cooperation among states
}

\author{
Benjamin Faude ${ }^{1}$ (D) Michal Parizek ${ }^{2}$
}

Accepted: 3 September 2020 / Published online: 9 September 2020

(C) The Author(s) 2020

\begin{abstract}
This paper analyzes how patterns of international cooperation are affected if a group of states, led by a major power, pursues a strategy of "contested multilateralism" (CM). We conceptualize $\mathrm{CM}$ as a reaction to deadlock in institutional adjustment bargaining where CM lowers the gains actors can reap from cooperation in the short run. We demonstrate that, in the long run, CM nevertheless can have positive effects on international cooperation and specify when this is the case. Because of the costs associated with it, CM conveys a credible signal of the resolve of a dissatisfied group of states to contest the institutional status quo. Due to this capacity, CM alters the institutional and strategic environment within which institutional adjustment bargaining takes place. As a result, CM opens up the possibility for inter-institutional accommodation that increases realized cooperation gains. We probe the plausibility of our theoretical reasoning with empirical case studies on competitive regime creation in multilateral development finance and on regime-shifting in the governance of international trade in genetically modified organisms.
\end{abstract}

Keywords Regime complexes · Contested multilateralism · International cooperation · Thickly institutionalized international system $\cdot$ Credible signaling

Electronic supplementary material The online version of this article (https://doi.org/10.1007/s11558-02009398-7) contains supplementary material, which is available to authorized users.

Benjamin Faude

b.faude@1se.ac.uk

Michal Parizek

michal.parizek@fsv.cuni.cz

1 London School of Economics and Political Science (LSE), Department of Government and Department of International Relations, Houghton Street, Holborn, London WC2A 2AE, UK

2 Faculty of Social Sciences, Institute of Political Studies, Charles University, Pekarska 16, 15800 Praha 5Jinonice, Czechia 


\section{Introduction}

World politics is replete with international institutions which create joint gains, but distribute those gains unevenly among states (Krasner 1991). An uneven distribution of cooperation gains often creates tensions in which those states gaining less than others demand institutional change. The most prominent case in point is the attempt of rising powers to induce change in the core institutions of the existing international order so that cooperation gains may be more evenly distributed among established and rising powers (Zangl et al. 2016). Over the past decade, rising powers have been acting to induce institutional change in major international institutions, including the World Trade Organization (WTO), the International Monetary Fund (IMF) and the World Bank (WB) (Hopewell 2015; Vestergaard and Wade 2015). Since established powers defended the institutional status quo rather successfully, China and its partners decided more recently to establish new international institutions, such as the Asian Infrastructure Investment Bank (AIIB), the New Development Bank (NDB) and the Chiang Mai Initiative Multilateralization Agreement. Thus, rising powers have responded to their dissatisfaction with the degree of change they have been able to effect within the existing institutional order by setting up a set of new international institutions which overlap in their competences with legacy institutions.

The tendency of states that are dissatisfied with the distribution of cooperation gains within an existing focal institution to establish a competing institution is by no means limited to rising powers. A group of countries led by Germany, for example, created the International Renewable Energy Agency (IRENA) because the International Energy Agency (IEA) distributed cooperation gains disproportionately towards countries with strong fossil fuel and nuclear industries (van de Graaf 2013). Similarly, a group of pro-whaling nations, led by Iceland and Norway, created the North Atlantic Marine Mammal Commission (NAMMCO) after a group of anti-whaling nations, led by Japan, had prevented institutional change that would have redistributed the cooperation gains created by the International Whaling Commission (Gillespie 2002). In addition, a group of states, led by the European Union (EU), which was dissatisfied by how the WTO distributed the joint gains realized through cooperation on international trade in genetically modified organisms (GMOs), established the Cartagena Protocol on Biosafety (Schneider and Urpelainen 2013).

These cases suggest that there is an overarching tendency for groups of states which, first, are dissatisfied by how a focal institution distributes cooperation gains and, second, prove unable to effectuate meaningful institutional change, to contest that focal institution by setting up an alternative institutional framework. In conceptual terms, such groups of states exercise contested multilateralism (CM) (Morse and Keohane 2014). The essence of CM is that a group of states strategically uses one international institution - existing or newly created - as an instrument to contest the governance activities of another international institution.

This paper analyzes how the strategies of CM impact on the ability of states to reap joint gains through institutionalized cooperation. We conceptualize CM as embedded in institutional adjustment bargaining between defenders and challengers of a given 
institutional status quo (Urpelainen and Van de Graaf 2014). ${ }^{1}$ Challengers are dissatisfied with the institutional status quo and thus seek to change the rules institutionalized within the focal institution - rules they perceive as favoring the defenders, a group that often includes the founders of the institution. ${ }^{2}$ Defenders, in contrast, are satisfied with the institutional status quo and thus seek to prevent change, as the rules inherited from the past favor their interests more than could any currently conceivable alternative. Against this backdrop, we understand the exercise of CM by the challengers of the institutional status quo to be a reaction to deadlock in institutional adjustment bargaining. Our premise is that deadlock results from challengers' inability to credibly communicate the degree to which they are resolved to challenge defenders over the institutional status quo. Faced with this inefficacy of "voice," challengers will choose partial "exit", shifting their efforts to another institution - existing or newly created - which they perceive, or deliberately construct to be, more conducive to their interests (cf. Hirschman 1970).

Since CM aims at "crafting rules in one elemental regime that are incompatible with those in another" (Raustiala and Victor 2004: 301-302), it erodes the causal mechanisms through which - according to the logic of "cooperation under anarchy" international institutions facilitate cooperation. $\mathrm{CM}$ breaks the convergence of expectations that define cooperation while it reduces the capacity of international institutions to serve as focal points among states (Drezner 2013). Thus, by re-introducing uncertainty about the behavior of actors, CM lessens the individual and collective gains states can capture through institutionalized cooperation.

However, we argue that precisely because it generates such costs, the exercise of $\mathrm{CM}$ can be an informative and credible signal that helps revitalize deadlocked processes of institutional adjustment bargaining. Because of the immediate political costs and risks outlined above, CM represents a clear signal of the challengers' dissatisfaction with the status quo and of their resolve to challenge it. At the same time, since CM is clearly distinct from reverting to unilateralism or bilateralism, it signals their continued interest in institutionalized cooperation. ${ }^{3}$ By sending these signals, CM changes the institutional and strategic environment for institutional adjustment bargaining. In doing so, it can help prompt defenders and challengers to find new cooperative arrangements. If such an arrangement is indeed arrived at, $\mathrm{CM}$ will re-create the gains states realize through institutionalized cooperation.

By fleshing this theoretical argument out, we contribute to developing a logic of "cooperation in a thickly institutionalized international system." That is, we update the

\footnotetext{
${ }^{1}$ In contrast to Morse and Keohane (2014: 385) who emphasize that their article offers "not an explanatory theory, but provides a useful framework for understanding changes in regime complexes and the strategies that generate such changes," the present paper fleshes out an explanatory approach which explicitly connects the logic of institutional proliferation to the logic of institutional accommodation in a single coherent theoretical approach. Our approach explicitly conceptualizes $\mathrm{CM}$ as a credible signal of dissatisfaction with a given focal institution. Morse and Keohane (2014: 391), by contrast, merely discuss credibility problems of the dissatisfied coalition as a reason for failed institutional adaptation.

${ }^{2}$ A focal institution is the "default institutional alternative" for addressing cooperation problems within a given issue area of international relations (Jupille et al. 2013: 9).

${ }^{3}$ Unilateral and bilateral responses may reflect the motivation to delegitimate extant institutions and/or to enhance the status or reputation of the challenging states. $\mathrm{CM}$, by contrast, is too costly to execute and to sustain, if the challenging states are not motivated to change the institutional underpinnings. Thus, given its costliness, exercising CM sends a clear and unequivocal signal of resolve to challenge the institutional status quo.
} 
well-established logic of "cooperation under anarchy" (Axelrod and Keohane 1985; Oye 1986) which revolves around two core assumptions: first, that international institutions are discrete entities which operate in isolation from one another and, second, that states pursue their interests and seek to maximize their payoffs through strategic action within individual institutions (Keohane 1984).

Neither of these assumptions is empirically fully accurate anymore. Contemporary international institutions are not discrete entities operating in isolation, but subject to inter-institutional influences and embedded in regime complexes (Alter and Raustiala 2018; Raustiala and Victor 2004). As a result, states gain opportunities to pursue interests and maximize payoffs not only within, but also across overlapping international institutions (Jupille et al. 2013). Those possibilities for cross-institutional action affect the ability of international institutions to facilitate cooperation among states in a way that cannot be accommodated in the logic of "cooperation under anarchy."

To develop the logic of "cooperation in a thickly institutionalized international system," we build on existing research which elucidates how states take advantage of regime complexes to pursue their own interests (Alter and Meunier 2009; Helfer 2009; Jupille et al. 2013; Morse and Keohane 2014). While this research develops the microfoundations for the theoretical analysis of international cooperation in the contemporary international system, it leaves unexplored the very fundamental question of how crossinstitutional action impacts patterns of international cooperation and the ability of states to reap joint gains. As indicated above, our key contribution lies in tackling this question by theorizing how strategies of contested multilateralism (CM) affect the realization of joint gains, through cooperation within formal international institutions.

The remainder of the paper is structured as follows: Section 2 situates our contribution within the burgeoning literature on what we call "cooperation in a thickly institutionalized international system." Section 3 conceptualizes CM as being embedded in institutional adjustment bargaining and theorizes how a lack of credible signals during institutional adjustment bargaining may lead to deadlock. We analyze the bargaining situation, illuminating its core features, by using a formal spatial model. Drawing on this model, Section 4 demonstrates how CM influences institutional adjustment bargaining. Moreover, it elaborates, theoretically, on how inter-institutional accommodation following CM may ultimately re-create joint gains realized through cooperation. In Section 5, we move to two case studies probing the plausibility of our theoretical reasoning for both variants of CM. We study, first, the creation of the AIIB as a competitor to the WB ("competitive regime creation") and, second, the shifting of the regulatory efforts in international trade in genetically modified organisms (GMOs) from the WTO to the Convention on Biological Diversity (CBD) ("regime shifting"). ${ }^{5}$ An appendix to the

\footnotetext{
${ }^{4}$ In a thinly institutionalized international system, states may equally decide to pursue cross-institutional action. Decisive for our argument is, however, that such actions are not captured by the theoretical logic of "cooperation under anarchy". To differentiate between "cooperation in a thickly institutionalized international system" and "cooperation under anarchy" therefore introduces an analytical distinction.

${ }^{5}$ In contrast to forum-shopping, regime shifting and competitive regime creation are collective strategies pursued by like-minded groups of states in order to shift, in their favor, the institutional underpinnings of international cooperation on a particular issue or in a particular issue area. Because of this commonality, Morse and Keohane (2014) conceive the two strategies as forms of contested multilateralism. Our theoretical logic applies to both variants of contested multilateralism which follow the same rationale and create the same implications for institutionalized cooperation. However, it does not apply to forum-shopping which is an individual strategy that does not aim at changing the institutional underpinnings of cooperation.
} 
article presents the results of a computer simulation which translates the static spatial model in Sections 3 and 4 into a dynamic setting of iterated interaction. ${ }^{6}$ Thus, the computer simulation carves out how temporal dynamics affect the impact of CM on the realization of cooperation gains. In doing so, it validates the robustness of our theoretical reasoning.

\section{Regime complexes, cross-institutional strategic action and international cooperation}

In the last decade, IR scholars have made considerable progress in understanding the cross-institutional strategies that states use to pursue their interests in a "thickly institutionalized international system." However, much existing research has neglected the implications of the different forms of cross-institutional strategic action for patterns of international cooperation (Busch 2007; Helfer 2009; Urpelainen and Van de Graaf 2014). Thus, our paper advances the (so far, very limited) literature which has begun exploring the fundamentally important question of how cross-institutional state action impacts prospects for international cooperation. On the one hand, Drezner (2013) argues that regime complexes undermine the capacity of international institutions to facilitate institutionalized cooperation because powerful states use their opportunities for cross-institutional action to avoid costly obligations. On the other, Gehring and Faude (2014) argue that cross-institutional strategizing gives rise to a functional division of labor among overlapping international institutions that stabilizes cooperation.

Both contributions develop, in the context of moving from "cooperation under anarchy" to "cooperation in a thickly institutionalized international system," theoretical mechanisms capable of explaining the two extreme outcomes possible: cooperation breakdown and inter-institutional stabilization of cooperation. However, neither contribution explicitly connects the logic of institutional proliferation to the logic of institutional accommodation in a single and coherent theoretical approach. Thus, IR research has yet to grasp the gradual effects on cooperation gains that lie between the extremes of cooperation breakdown and its inter-institutional stabilization, and which are largely determined by the particular characteristics of institution-overarching interactions among groups of states.

We start to close this gap by synthesizing the two existing approaches. Whereas Drezner (2013) assumes that states exploit possibilities for cross-institutional action without taking the implications for international cooperation into account, Gehring and Faude (2014) assume that states care primarily about the implications of their crossinstitutional behavior on international cooperation. These different analytical starting points lead directly to the authors' opposing conclusions. In contrast, we integrate negative and positive implications of cross-institutional action into a single coherent theoretical logic. This approach allows us to infer - contra Drezner - that although cross-institutional action is likely to be detrimental to cooperation in the short-term, cooperation breakdown is by no means inevitable. Moreover, in contrast to Gehring and Faude, our approach is able to explain inter-institutional coordination without

\footnotetext{
${ }^{6}$ The online Appendix is available on the Review of International Organizations's webpage.
} 
assuming that states avoid cross-institutional actions detrimental to the ability of international institutions to facilitate cooperation.

\section{$3 \mathrm{CM}$ as a result of failed institutional adjustment bargaining}

We start by outlining a comprehensive analytical framework embedding $\mathrm{CM}$ in a situation of failed institutional adjustment bargaining.

\subsection{Deadlocked institutional adjustment bargaining}

Our starting point is a situation in which cooperation in the existing focal institution creates gains that both defenders and challengers are interested in. At the same time, the gains realized through cooperation in a focal institution are distributed unevenly among the two groups of states (Krasner 1991). This uneven distribution creates tensions in which those states gaining less demand institutional change. As a result, institutional adjustment bargaining becomes necessary.

For various theoretically grounded reasons, such institutional adjustment bargaining may fail. First, a belief in the longevity of a focal institution and knowledge of the importance of the collective goods it produces may lead states toward overly confrontational negotiating strategies. Conflict over the redistribution of cooperation gains may trump the common interest in creating cooperation gains in the first place (Lax and Sebenius 1986; Fearon 1998). Second, institutional developments are path-dependent (Pierson 2004). Thus, institutional adjustment bargaining may lead to deadlock even when efficiency gains are available; this is because, as it evolves, an institution will endogenously create an interest in keeping it stable among a large number of its members. Third, an international institution may not only strongly favor a particular segment of its members, but indeed be captured by this group and its private interests (Urpelainen and Van de Graaf 2014). If so, institutional adjustment bargaining is unlikely to lead to a commonly acceptable outcome.

In spite of the merits of these specific problems, we believe there is one theoretically more fundamental, and substantially important, reason why institutional adjustment bargaining may systematically fail: information asymmetry. Since the true level of resolve to challenge the focal institution is information private to the challengers, they may fail to credibly communicate their resolve (Morrow 1999). The defenders are inherently uncertain about factors such as the challengers' perception of the distribution of cooperation gains, the location of their red lines in the institutional adjustment bargaining, or the degree to which they're discounting future gains (Narlikar and Van Houten 2010). In short, the defenders cannot know exactly how prepared the challengers are to seriously take on the institutional status quo. As a result, the defenders may miscalculate rationally "due to lack of information" and underestimate challenger resolve (Fearon 1995: 381; cf. Morrow 1994). If so, the lack of credible signals will lead to deadlock and to the two groups being unable to realize institutional adjustment as an alternative outcome - a resolution that both sides would actually prefer (Fearon 1995).

A lack of credible information is theoretically fundamental for explaining failure in institutional adjustment bargaining (Morrow 1999). It sheds light on why conflict over 
the distribution of cooperative gains prevents their creation in the first place. It can also explain why a group of states which profits disproportionately from the increasing returns created by an international institution over time is not able to strike a deal which ensures the operability of that institution despite contestation. Moreover, a lack of credible signals can explain why a group of states which has captured an international institution, and is therefore able to distribute the costs and benefits among its members, may not be able to do so in a way that keeps the institution operable.

\subsection{The responses to deadlock in a "Thickly Institutionalized International System" and the costs of $\mathrm{CM}$}

Under the theoretical logic of "cooperation under anarchy," two extreme choices are available to the challengers when institutional adjustment bargaining becomes deadlocked. On the one hand, they may decide to formally exit the institution and turn to unilateralism. On the other hand, the challengers may stay within the institution and continue to participate in its activities while possibly seeking to continuously challenge it from within.

The logic of "cooperation in a thickly institutionalized international system" opens the space for a third reaction to deadlock in institutional adjustment bargaining: resorting to CM. That is, the logic of "cooperation in a thickly institutionalized system" accounts for the possibility that the challengers may try to realize their interests by creating a new institution ("competitive regime creation"), or by shifting their efforts to adjust the institutional structure to another existing institution, with a mandate overlapping with that of the focal institution ("regime shifting") (Morse and Keohane 2014). CM therefore represents an alternative to the two possible reactions to deadlock envisaged by the logic of "cooperation under anarchy."

The exercise of $\mathrm{CM}$ enables the reigniting of institutional adjustment bargaining, previously deadlocked, but it also creates two types of costs: initial (fixed) setup costs that will need to be borne by the challengers, and the continuous long-term costs attached to cooperation that will be faced by both challengers and defenders. Each of these costs lie - implicitly or explicitly - at the core of the pessimistic view on CM.

First, to exercise CM, the group of dissatisfied states must be able to absorb the costs that accrue from the process of establishing a new international institution or from expanding the mandate of an already existing one. Both variants of CM are the costliest institutional choices among those available in a thickly institutionalized international system, as discussed by Jupille et al. (2013: Chapter 2). Political capital needs to be spent, reputation invested, and possibly tough negotiations among those engaging in $\mathrm{CM}$ need to be conducted, all this with often uncertain results as both CM strategies are risky to undertake. They only yield a significant amount of joint gains if a sufficiently large number of states decides to support them (Schneider and Urpelainen 2013).

The participation of a major power in the process significantly elevates the likelihood that the challengers are able to surmount these hurdles. A major power offers focal point solutions and the resources necessary to put a viable institutional arrangement in place. It will wield an arsenal of sticks and carrots to incentivize less powerful states to join the new institutional arrangement or else accept expansion of the mandate of an existing institution (Lake 2009; Schneider and Urpelainen 2013). A major power is therefore in a good position to ensure that there will be enough political support to 
make the new institutional arrangement viable. By establishing a roughly symmetrical power distribution between challengers and defenders, it also prevents the latter from simply imposing their will on the former and from ignoring their demands.

Second, moving to the long-term costs, CM is not only costly and risky to execute but also potentially very costly to sustain. By exercising $\mathrm{CM}$, states craft rules in one international institution that are incompatible with those in another. Thus, CM inevitably creates "strategic inconsistency" (rivaling rules), as discussed by Raustiala and Victor (2004: 301-302). As a result, states gain greater leeway in determining their own behavior. Inherent in strategic inconsistency is therefore a misalignment of behavioral expectations and, by implication, a reduction of the realized cooperation gains. In other words, the existence of two sets of rivaling rules effectively erodes the very purpose of cooperation, where both groups abide by a common set of rules, increasing the predictability of their behavior and thus creating space for the mutual alignment of expectations. In this vein, four specific ways in which strategic inconsistency undermines cooperation gains may be identified (Drezner 2013: 283-290): it dilutes the "power of previously constructed focal points"; it raises the costs of monitoring defections from existing institutions; it weakens "actors' overall sense of legal obligation"; and it raises "the costs of national compliance with international mandates with more severe resource constraints." The core of the problem CM creates for cooperation lies precisely in the misalignment of behaviour and expectations as these negative effects kick in.

Our theoretical logic is sufficiently general to apply not only to international institutions with purely regulatory purposes, but also to international institutions with operative purposes. Even in institutions with predominantly operative targets, the core of the political conflict often lies in how the operations are carried out, who bears the costs and who receives the benefits. This is exemplified by the case of multilateral development finance discussed in Section 5.1.

While this problem is not central to our argumentation, we should also highlight that the size of the costs of $\mathrm{CM}$, and its attractiveness, varies systematically across issue areas. It depends on the degree to which an issue-area is characterized by network effects and barriers to entry (Lipscy 2017): The lower the network effects and barriers to entry, the higher the incentives to cooperate through a differentiated institutional framework (Lipscy 2017: Chapter 2). The attractiveness of CM varies accordingly: The higher the incentives to cooperate through a differentiated institutional framework, the higher the attractiveness of $\mathrm{CM}$ for states that are dissatisfied with the institutional status quo (Lipscy 2017: Chapter 2). By implication, the higher the attractiveness of $\mathrm{CM}$, the higher the challengers' bargaining leverage already in intra-institutional adjustment bargaining. Incomplete information about challengers' level of resolve explains why $\mathrm{CM}$ also occurs when defenders know it is an attractive option for challengers.

\subsection{Spatial model}

Our informal discussion suggests that CM brings about important short- and long-term costs. To understand the effects of $\mathrm{CM}$ on cooperation more precisely, we now start to develop a spatial model that will help us extract the essence of CM as a bargaining situation (see Hinich and Munger 1997 for an overview of the spatial modeling 
techniques we follow). Based on the model, we are able to formulate a specific proposition summarizing our key insights into $\mathrm{CM}$ as a case of a bargaining failure.

The first step in the development of the model is the identification of the actual dimension of contest between challengers and defenders, whom we treat as internally cohesive collective actors that are equally powerful. Within institutional adjustment bargaining, the core of political contestation lies in the amount of behavioral adjustment each of the two group actors is expected to undergo in response to particular institutional provisions, as contrasted with each group's preferred behavior. Cooperation is defined as the mutual adjustment of patterns of state behavior against the backdrop of discord. It requires that the actions of separate states are "brought into conformity with one another through a process of negotiation" (Keohane 1984: 51). In our case of institutional adjustment bargaining, cooperation is achieved if a group of defenders and a group of challengers (partially) adjust their behavior toward the preferences of the other side.

The second core feature of our model is the divergence between Defender and Challenger on the exact shape of the common behavioral pattern and its distributive effects. Formally, we capture this disagreement in the spatial model in Fig. 1. The axes depict the amount of patterned behavioral change by each of the two actors as described in the previous paragraph: on the horizontal axis for the Challenger, on the vertical axis for the Defender. In line with the conflicting interests over the distribution of cooperation gains, the ideal point for the Challenger group $\left(\mathrm{C}^{*}\right)$ is located at maximum behavioral adjustment by the Defender group, and only at limited adjustment of the Challenger's own group behavior. Analogously, the Defender (D*) prefers maximum adjustment by the Challenger, but minimal adjustment of its own behavior. Points D'

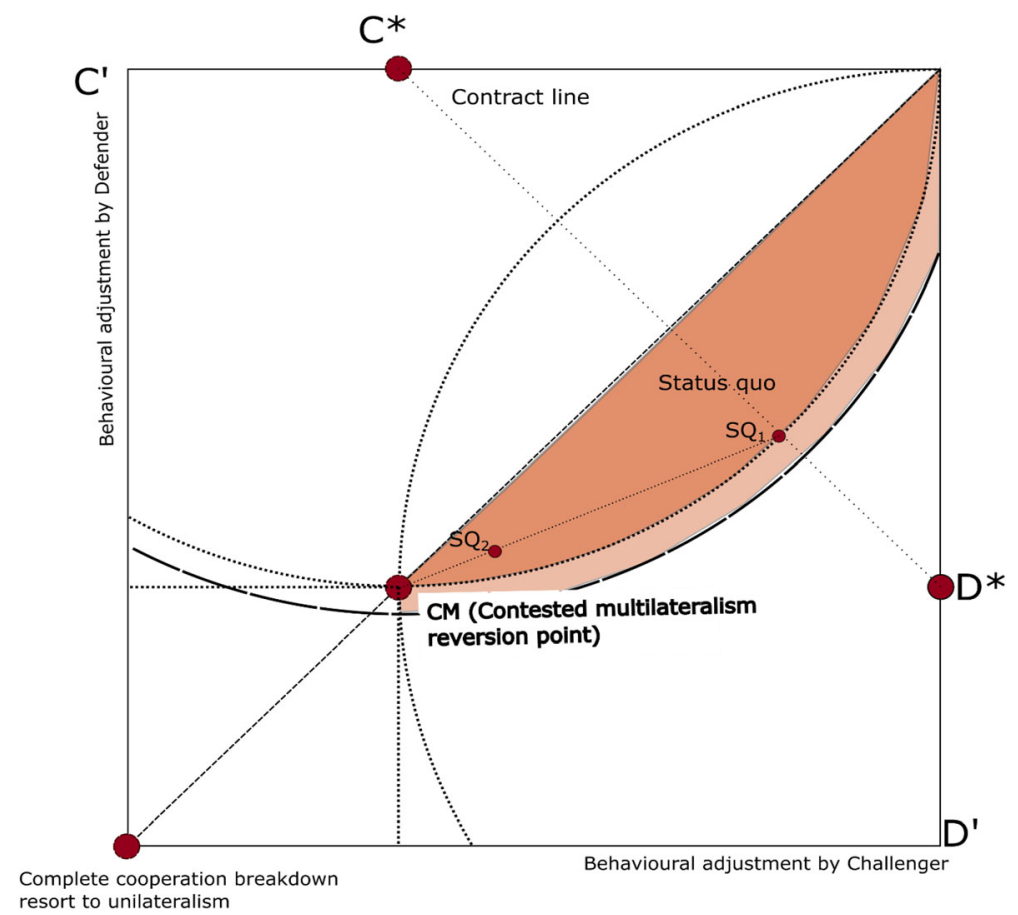

Fig. 1 Spatial analysis of the CM situation 
and $\mathrm{C}^{\prime}$ denote the respective unilateral outcomes where Challenger and Defender free themselves of all constraints, even within their own groups; these points will not directly enter our analysis.

Throughout our modeling exercise we assume linear utility functions, where an actor's utility decreases proportionately to the distance of an outcome from its respective ideal point. The utility of the Defender from an institutional outcome $X$ is thus given by the utility function $U_{D}^{X}=-d\left(D^{*} ; X\right)$ and the utility function of the Challenger by $U_{C}^{X}=-d\left(C^{*} ; X\right)-c_{f}$. In both cases, the component $d\left(A^{*} ; X\right)$ stands for the Euclidean distance between outcome $X$ and actor $A$ 's ideal point (where A is either Defender D or Challenger C). The component $c_{f}$ denotes the fixed costs accrued by the Challenger in case it chooses to engage in CM, as discussed above.

As the third and last key feature, we are able to locate in our model the two most important possible states of the actors' interaction when $\mathrm{CM}$ is considered by the Challenger. The first is the initial status quo. The 45-degree line in Fig. 1 identifies all points of possible agreement between Challenger and Defender that are equitable. Because the initial status quo favors the Defender, it is located in the triangle below the 45-degree line. We will assume that it lies within the colored area delineated by the Challenger's indifference curve cutting through the CM reversion point (i.e. within the arc centered at the Challenger's ideal point). We mark the status quo with $S Q_{1}$. If it were to lie outside the circle, the status quo would be extremely biased, allocating (almost) all gains to the Defender. Then a move to $\mathrm{CM}$ would be immediately beneficial to the Challenger and the situation would not be particularly interesting from an analytical point of view.

The second crucial point in Fig. 1 is the exercise of CM itself, understood as a reaction to the initial failure of institutional adjustment bargaining. When the Challenger fails to convince the Defender to agree to an adjustment of the focal institution, it seeks to break the deadlock and to realize its interests by setting up a new institution or by shifting activities to an existing one which better reflects its preferences. It thus departs from the prescribed behavioral pattern in the focal institution, shifting towards its ideal point, $C^{*}$. This point reflects the agreement within the Challenger group on a smaller amount of required behavioral adjustment among its members. Expectedly, the Defender will respond in kind to avoid being a "sucker" in the focal cooperation arrangement. It will shift to the level of behavioral adjustment corresponding to $\mathrm{D}^{*}$. Both actors thus converge to a less cooperative outcome $\left(\mathrm{C}^{*}, \mathrm{D}^{*}\right)$, corresponding to the Nash equilibrium in a classical one-off prisoner's dilemma game. Under this point, labeled CM, both groups free themselves from much of the constraints formerly imposed by the rules enshrined in the focal institution. For the sake of completeness, we can also identify analogously the complete cooperation breakdown situation, located at the intersection of the Defender's and Challenger's unilateral options $\left(\mathrm{C}^{\prime}\right.$, D') ${ }^{7}$

The model highlights that the move to CM brings about sizable costs. It manifestly lowers the cooperation gains for the Defender, whose utility drops drastically, as the CM outcome is significantly farther away from its ideal point than the initial status quo. More interestingly, it also lowers the cooperation gains for the Challenger. The size of

\footnotetext{
${ }^{7}$ In our model, this outcome does not directly enter the actors' calculations, as they can always count on cooperation at least within their respective groups.
} 
the long-term loss of its gains depends on how biased the initial status quo was, but unless the initial bias was extreme, providing (almost) all gains to the Defender, the Challenger is bound to face immediate losses as both actors move to the inefficient noncooperative CM situation. This is all the more the case because of the fixed transaction costs of establishing the new institution, or engaging in the shift to an already existing institution. These fixed transaction costs are denoted by the larger arc centered at $\mathrm{C}^{*}$. In sum, Fig. 1 shows that unless the status quo is extremely biased in favor of the Defender, the resort to CM results in a net loss for both Challenger and Defender. Under all circumstances it represents a collective loss. We formalize our reasoning in the following proposition:

Proposition 1 Compared to following the status quo, the resort to CM brings about an immediate loss of gains reaped collectively by the challengers and defenders, and under all but the most extreme initial situations also for each group individually.

As hinted at above, Fig. 1 also highlights that how sizable the costs of CM are depends on how cooperative the status quo actually was. If the status quo lay on or close to the contract line connecting points $\mathrm{C}^{*}$ and $\mathrm{D}^{*}$, such as $S Q_{1}$, the losses would be more sizable than e.g. from the point located at $S Q_{2}$. This is very important, because - even if CM is not exercised - the focal institution is unlikely to maintain its performance and to ensure high levels of compliance in the long term, if the cooperation gains that it creates continue to be distributed in a highly asymmetric way. In case the increasing dissatisfaction of the Challenger leads to declining compliance with the provisions of the focal institution, the status quo would rather shift, over time, from the more cooperative situations to those with fewer cooperation gains produced, such as at $S Q_{2}$. Under these circumstances, a choice of CM would represent a lower decline in cooperation gains.

Since a static spatial model does not allow us to account for such temporal dynamics, the appendix to this article presents an extensive computer simulation in which the spatial model is translated into an iterated game. The computer simulation evaluates the Defender's and Challenger's long-term discounted gains (or costs) from pursuing CM, in contrast to sticking to the focal institution, over high number of interaction rounds. The simulation allows us to conclude that the central theoretical claims developed so far hold not only in the static constellation depicted by the spatial model, but also when the temporal dynamics described above are taken into account.

\section{$4 \mathrm{CM}$ as a credible signal and institutional adjustment bargaining in a new environment}

Having discussed the effects of CM that are detrimental to cooperation, this Section develops our theoretical framework further by elaborating on those effects of CM that are conducive to cooperation. First, we demonstrate why CM sends a credible signal of a challenger's resolve to contest the institutional status quo, altering the informational and strategic environment of institutional adjustment bargaining. Second, 
by outlining a path through which inter-institutional accommodation between focal and challenging institution can be accomplished, we show how the previously lost cooperation gains can be re-created.

\subsection{CM as credible signaling}

In our theoretical logic, $\mathrm{CM}$ results from a deadlock in institutional adjustment bargaining caused by the inability of a challenger to credibly communicate to a defender its level of resolve to contest the institutional status quo. At the same time, the very act of CM dramatically reduces the information asymmetry problem. As CM constitutes a highly credible signal of the challengers' resolve to contest the status quo, it helps ameliorate the conditions that led to its exercise in the first place.

In political communication a signal is credible to the degree that it is (potentially) costly for the actor who sends it (Fearon 1995; Morrow 1999). Within institutional adjustment bargaining, then, the communication of the challengers' resolve is credible if it leads them to suffer a loss of cooperation gains. In line with this expectation, challengers have a set of mechanisms at their disposal to communicate to defenders their resolve to contest the institutional status quo. First, they may utter dissatisfaction within the existing institution, that is, exercise "voice". Since the costs attached to mere voice expression are usually low, they constitute little more than cheap talk. Thus, challengers communicate only a low level of resolve when exercising it. Second, and more profoundly, challengers may gradually stop complying with the rules enshrined in the focal institution. In contrast to "voice," gradual non-compliance reduces cooperation gains. However, the gradual nature of the process strips it of its ability to credibly signal an immediate, high level of resolve. On the contrary, the lengthiness of the process may indicate, at least in the short term, that the challenger is in fact unready to resolutely confront the institutional status quo with radical disruptive action. The same is true if challengers start to obstruct the institution's decision-making or to block individual operations.

Third, challengers may decide to exercise CM. As we discussed above, such a choice is politically risky and immediately costly for challengers. It imposes on them the sizable costs of institutional creation (with competitive regime creation) or adjustment (with regime shifting). Most profoundly, in the long-term, CM reduces the cooperation gains by deliberately creating "strategic inconsistency" (rivaling rules) which breaks the convergence of expectations about states' behavior (Raustiala and Victor 2004: 301-302). It raises the transaction costs of cooperation as "strategic inconsistency" (rivaling rules) creates the need to navigate through a thicker, less organized and therefore more confusing web of institutionalized rules.

Taking into account all these costs, and its rather abrupt nature, a high level of credibility is inherent in exercising CM. In other words, only highly resolved actors may be expected to exercise CM in order to contest a given institutional status quo. ${ }^{8}$ It thus eliminates much of the information asymmetry problem that led the challengers to

\footnotetext{
${ }^{8}$ In this vein, while challengers have an incentive to claim they will pursue CM even when unwilling or unable to do so (Morse and Keohane 2014: 391), only the exercise of CM reduces cooperation gains. That is, only its actual pursuance is costly and thus able to send to the defenders a credible signal of the challengers' resolve (Fearon 1995).
} 
exercise $\mathrm{CM}$ in the first place. Moreover, $\mathrm{CM}$ can be read as testifying to the challengers' seriousness about institutionalized cooperation. That is, the exercise of CM signals a commitment to multilateralism as opposed to reverting to unilateralism or bilateralism. It thus shows the degree of the challengers' resolve to contest the status quo, but it also highlights their readiness to engage in multilateral cooperation, albeit on more equitable terms.

To be sure, the exercise of CM also creates benefits for the challengers, if it is conducted successfully. Under regime shifting, they gain the opportunity to approach an issue from the governance objective of a different international institution. Under competitive regime creation, the challengers gain the opportunity to design a new institutional arrangement according to their own interests and power resources. However, the fact that these benefits may become available to the challengers, if $\mathrm{CM}$ is carried out successfully, does not alter the key underlying nature of CM. It represents a mechanism that creates principal costs by reducing the degree of mutually beneficial behavioral adjustment among actors and, by implication, the predictability of their behavior. In spite of specific immediate benefits, the key effect of CM is the break-up of the convergence of actors' expectations, as highlighted in Fig. 1. Unless cooperation between the challengers and the defenders re-emerges at some point, the costs associated with CM clearly outweigh the benefits.

When $\mathrm{CM}$ is exercised successfully, institutional adjustment bargaining can be expected to re-open. At this point, the positive effects of CM start to materialize. First, the fundamental uncertainty about the challengers' resolve will have been dramatically reduced. The bargaining may thus become more information-rich and efficient (Narlikar and Van Houten 2010). Second, the act of CM changes the strategic environment within which institutional adjustment bargaining takes place. Compared to the previous situation, the challengers' bargaining position is now stronger and the defenders cannot hope to one-sidedly dominate institutional adjustment bargaining. CM not only boosts the credibility of the challengers' position but also provides an alternative institution within which they can independently realize at least some cooperation gains. In short, CM improves the challengers' outside options. Moreover, by creating rivaling rules ("strategic inconsistency"), CM imposes negative externalities on the defenders, as it weakens their ability to reap the gains they used to reap in the focal institution. All in all, thus, the act of CM re-opens the deadlocked institutional adjustment bargaining, though on different terms, that is, with two competing institutions.

\subsection{The path to re-creating cooperation gains}

If cooperation gains are to be re-created, the two competing sets of provisions need to be brought into (at least partial) conformity. A working compromise between the two institutions needs to be found.

On the one hand, both defenders and challengers prefer such institutional realignment and the re-creation of cooperation gains to enduring "strategic inconsistency". In spite of having achieved their target of establishing rivaling rules, the challengers remain members of the focal institution. As long as their conflict with the defenders reduces the amount of cooperation gains, they are able to reap, as discussed in Section 3, the challengers gain an interest in the operability of both institutions and, 
by implication, in realigning the rivaling rules. The same applies to the defenders who lost sizably due to the exercise of CM, and now gain a chance to reclaim parts of the lost cooperation gains. One the other hand, each group favors a different form of institutional realignment: the defenders favor a solution close to the cooperative arrangement established by the focal institution, while the challengers prefer a solution close to the cooperative arrangement realized by the institution that they used or created to exercise CM. Thus, the two sides find themselves in a "Battle of the Sexes" situation (Snidal 1985: 931-936; Fearon 1998).

A solution to this particular Battle of the Sexes problem can be reached through a process of gradual inter-institutional accommodation. That is, the issue can be solved within a sequential game where, in each stage, partial concessions are exchanged and the newly created gains are cemented. Analogous to the classical logic of "the evolution of cooperation" (Axelrod 1981; Axelrod and Keohane 1985), a series of piecemeal institutional adjustments may, over time, lead to a realignment of the regulatory activities of the rivaling institutions. Thus, what we have in mind is an evolutionary process within which either defenders or challengers start to accommodate their own institution, through formal and collectively binding adjustments of rule sets, in ways that gradually eliminate strategic inconsistency, and the other side then responds in kind by adapting its institution accordingly. Figure 2 visualizes our reasoning in the spatial model presented earlier in Fig. 1. The initial cooperative arrangement, the status quo, dissolved into two competing institutions under CM. Due to the signaling quality of

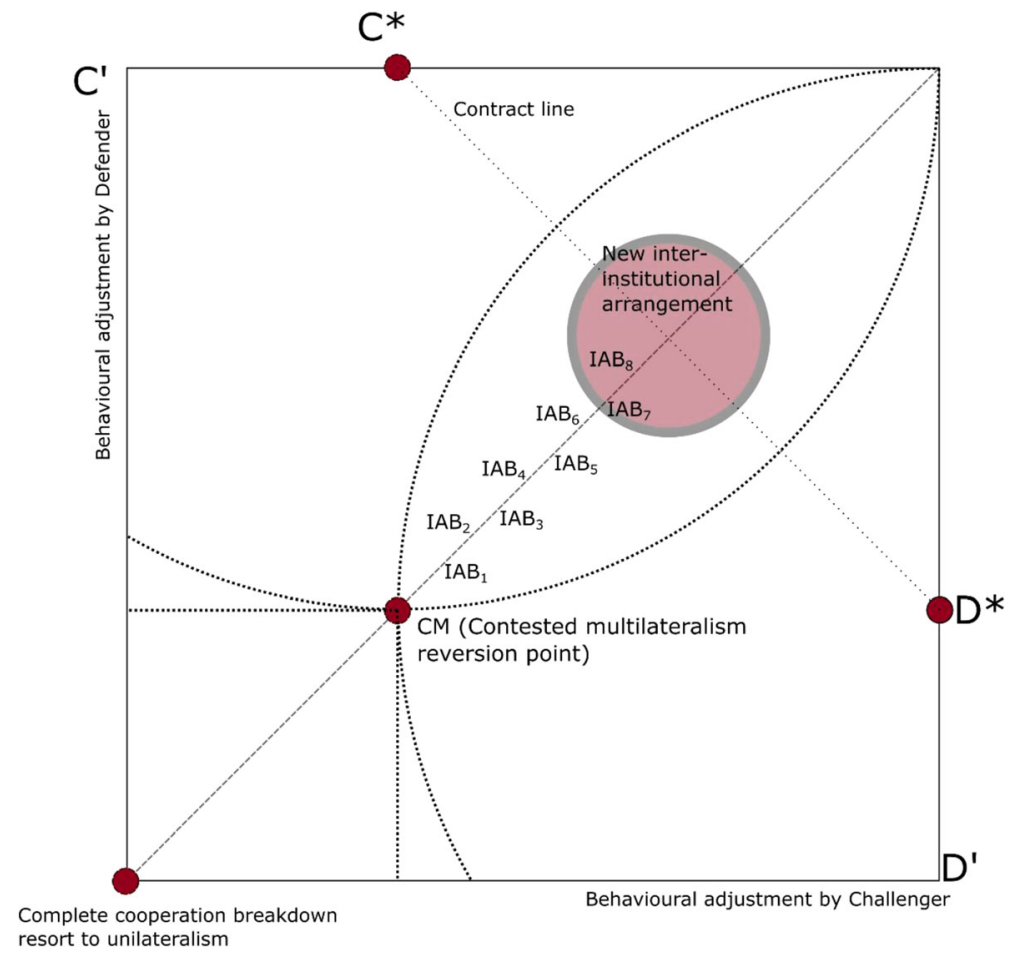

Fig. 2 The path of contested multilateralism: from status quo, to reversion point, to a new inter-institutional arrangement 
$\mathrm{CM}$, institutional adjustment bargaining (IAB) can now be reopened under altered informational and strategic circumstances. In an iterative process marked with points $\mathrm{IAB}_{1}-\mathrm{IAB}_{8}$, a new cooperation scheme may emerge over time. As discussed above, both camps are similarly powerful, and since they reach the new cooperative arrangement in a highly iterated setting, the latter is likely to distribute cooperation gains symmetrically. This possible outcome, marked as "New inter-institutional arrangement" in Fig. 2, expresses the core of the positive effect $\mathrm{CM}$ may have on cooperation.

The outcome of inter-institutional complementarity may take two basic forms. First, inter-institutional accommodation may lead the (formerly) rivaling institutions to exercise their respective governance functions in mutually complementary ways. That is, the process may lead to the emergence of an institution-overarching governance system that accommodates the formerly rivaling institutions. By implication, both institutions continue to operate in the area of overlap, but they find the means to resolve their rivalry in a way that enables complementary co-governance. Second, the process of inter-institutional accommodation may lead the overlapping institutions to delimit their jurisdictions in a way that effectively eliminates overlap and, by implication, their rivalry. If it is realized in this form, inter-institutional accommodation dissolves the area of overlap by subdividing it into distinct parts that are each governed exclusively by one institution (Gehring and Oberthür 2009).

No matter which of these two forms of inter-institutional complementarity is reached, the cooperation gains that got lost through the pursuance of CM can be recreated in two steps. First, CM helps to reopen deadlocked institutional adjustment bargaining, since it provides a credible signal of the true level of the challengers' resolve. Second, after CM has taken place, the two groups of actors involved may engage in a process of gradual inter-institutional accommodation because they will share an interest in reaping previously lost cooperation gains. Taken together, these two critical features of CM lead us to formulate the following proposition:

Proposition 2 CM may have positive long-term effects on cooperation because it conveys a credible signal of the challengers' resolve, which helps break deadlock in institutional adjustment bargaining, and induces a process of mutually complementary institutional adaptation.

Similar to Proposition 1, Fig. 2 highlights that the ability of actors to recreate cooperation gains that got lost initially due to $\mathrm{CM}$ will depend on timing, in particular on how long it takes them to reach inter-institutional complementarity. If actors are able to reach the state of complementarity very soon after the exercise of CM, only a few gains will be lost. By contrast, if they are stuck in the non-cooperative CM outcome for long and inter-institutional complementarity is only slowly arrived at, the costs of CM will be higher.

Since the static spatial model does not allow us to capture the temporal dynamic of this process (compare Section 3.3), the appendix to this article presents a computer simulation which explicitly adopts a dynamic perspective. This computer simulation lends support to the reasoning developed in this Section that the cooperation gains that got lost through the exercise of CM may be recreated, if CM triggers a process of mutually complementary institutional adaptation. Moreover, it identifies the conditions under which this is the case. In sum, the computer simulation provides a robustness 
check that the theoretical reasoning developed in Section 4 holds not only in a static, but also in a dynamic setting.

\section{The effects of $\mathrm{CM}$ on patterns of cooperation: Empirical analysis}

In this Section, we present two case studies to probe the plausibility of our theoretical reasoning: from development finance, the case of the WB and the AIIB, and from international trade, the case of the WTO and the CBD. As is well-known, plausibility probes serve an important function in theory development as an intermediate step between hypothesis generation and hypothesis testing (Eckstein 1975). They are particularly suitable to advance "[n] ew and relatively untested research programs," such as the one on cooperation in a thickly institutionalized international system (George and Bennett 2005: 251).

The empirical cases studied in the remainder of this section are selected from a universe of cases which encompasses all those instances in which a group of states which was dissatisfied with the distribution of cooperation gains within an existing focal institution decided to exercise CM after institutional adjustment bargaining had failed. Out of this universe of cases, we selected two empirical cases according to the following criteria: First, we chose to analyze cases which allow us to maximize variation on a range of dimensions that we expect to have a systematic effect on how the exercise of CM impacts the realization of cooperation gains. Thus, our two cases include a) both variants of CM: "competitive regime creation" (development finance) and "regime-shifting" (trade in GMOs), b) strategic interaction between different types of actors: in the WB/AIIB case, a group of established powers led by the US interacts with a group of rising powers led by China, whereas in the WTO/CBD case, both groups are led by established powers, namely the US and the EU; c) "strategic inconsistency" not only in different issue-areas, but also between different types of international institutions: the WB and the AIIB fulfill operative purposes, whereas the WTO and the CBD perform regulatory functions, d) the two different types of interinstitutional accommodation described in Section 4.2: co-governance in the WB/AIIB case and jurisdictional delimitation in the WTO/CBD case. Second, by selecting cases which both feature significant distributional conflicts between major powers, we made sure that we analyze empirical cases which are not biased towards our theoretical argument that, under certain conditions, CM can have a positive effect on international cooperation. While we do not claim that these cases constitute "least-likely cases" for our theoretical argument, we are confident that, since both of them feature distributional conflicts between major powers, they are not biased towards a positive outcome. Having selected our cases according to these criteria enables us to claim that our two empirical case studies corroborate a theoretical argument that applies to a broader universe of cases (see Conclusion for scope conditions) without subjecting it to a rigorous test.

In each case study, we start by highlighting the nature of the conflict between defenders and challengers, then continue to describe the process of CM and identify the costs involved in the process, in line with our Proposition 1. After that, we turn to the process of inter-institutional accommodation theorized in Proposition 2. 


\subsection{CM in the global governance of development finance: The WB and the AllB}

On 16 January 2016, a group of 57 states led by China opened the AIIB for business. This exercise of CM in the form of "competitive regime creation" resulted primarily from China's efforts to put pressure on the defenders of the institutional status quo in the WB. ${ }^{9}$ It was a reaction to a reform of voting shares in the WB that proved insufficient to accommodate the rise of China and other Non-Western states, continuing to severely under-represent them, in their view (Yang 2016: 766). ${ }^{10}$ In this regard, the creation of the AIIB was analogous to the creation of the NDB by the five BRICS countries.

How did China arrive at this exercise of CM? Starting in 2010, China vehemently voiced discontent that its increase in economic power and financial contribution to the WB did not translate into greater WB vote shares. ${ }^{11}$ True, the WB underwent a "voice reform" to increase the voting powers of developing states. In 2010, the Bank announced that developing and transition countries increase their voting power from 42.60 to $47.19 \%$ and developed countries reduce their share from 57.40 to $52.81 \%$ as part of a deal struck during the Great Recession (Vestergaard and Wade 2015: 6). China thus became the largest shareholder after the US, Japan, South Korea, Turkey, and Mexico. Nevertheless, the changes in the WB's decision-making rules did not satisfy the world's second largest economy's longing for more equitable vote distribution. Its efforts to redistribute influence in the WB more significantly were proving unsuccessful.

To be sure, the creation of the AIIB was motivated also by the desire to close the funding gap in regard to infrastructure development in Asia (estimated to be about $\$ 8$ trillion between 2010 and 2020) that existing institutions proved unable to close (Reisen 2015). However, if China's primary objective would have been to boost funding in infrastructure development in Asia, a much less costly and risky solution would have been to increase its capital subscription to the Asian Development Bank, which already spent more than half of its budget on infrastructure (Wilson 2019: 165). However, China decided to take the more demanding path, creating the AIIB, to demonstrate its resolve to contest the institutional status quo in the $\mathrm{WB} .^{12}$

As a result, on October 24, 2014, China signed an agreement to establish the AIIB together with 21 Asian states which are simultaneously members of the World Bank. Especially given the US campaign against joining the AIIB, it was by no means certain that the AIIB would be able to attract many members (Freeman 2019). It was therefore not only costly but also risky for China to exercise CM by establishing the AIIB. In

\footnotetext{
${ }^{9}$ China not only proposed the AIIB, but is also its largest financial contributor, holds veto power on all questions relating to the governance of the Bank and hosts its permanent headquarter.

${ }^{10}$ Moreover, institutional reform in the IMF was stalled in the US Congress for five years. Some commentators, such as Oliver Blanchard, former Chief Economist of the IMF, and Larry Summers, former Chief Economist of the World Bank, consider the long delay in the implementation of the IMF reform as an integral part of the dissatisfaction with the institutional status quo that led China to create the AIIB (Mackintosh 2016: 27-28; Summers 2015). For the theoretical argument of this paper it does not matter whether China's dissatisfaction with the institutional status quo referred to the WB alone or to both Bretton Woods institutions.

${ }^{11} \mathrm{http}: / /$ www.worldbank.org/en/country/china/overview

${ }^{12}$ Importantly for our argument, China chose to create a multilateral development bank. Alternatively, it could have decided to use its policy banks, such as the China Development Bank and China EXIM Bank to close the infrastructure gap in Asia. That it created the AIIB instead signifies a commitment to multilateral cooperation.
} 
spite of that, the Bank proved able to attract considerable support in other world regions, most notably in Europe. ${ }^{13}$ Today, the AIIB has 102 approved members (which include many members of the WB and some close allies of the US), making it the world's second-largest MDB. With an initial paid-in capital stock of $\$ 100$ billion, the AIIB focuses on international development financing for infrastructure projects in the Asian region.

At the same time, China enjoys a dominant position in the Bank. It possesses $26.64 \%$ of the vote shares, which contrasts with the $4.45 \%$ of the vote shares it holds in the WB. ${ }^{14}$ Thus, the creation of the AIIB increased the leverage of China (and other Non-Western members) within the WB. In short, China resorted to "competitive regime creation" in response to its dissatisfaction with the institutional status quo in the WB and a reform of its governance structure which it perceived to be too meager (Knoerich and Urdinez 2019: 341, 353).

In line with Proposition 1, a number of negative effects on international cooperation in development finance was expected by major actors. The worry of many was that by giving Non-Western borrowers more institutional choices, the AIIB weakened the bargaining position of Western donors and the WB's enforcement mechanism. The availability of an alternative source of developing financing means that borrowing countries have weaker incentives to comply with the terms and conditions set out by the WB (Reisen 2015: 88).

To highlight the perceived dangers represented by the AIIB's creation to the existing order, China's exercise of CM has been described as "a masterful diplomatic coup, arguably the most ambitious project of multilateral institution-building to be accomplished by a non-Western power after the end of the Cold War" (Andornino 2019: 605). The AIIB constitutes "China's first major foray into leading an international organization with global membership" and thus "an extraordinary development in global governance" (Gutner 2019: 2). At the same time, it has been seen as being part of "China's shadow global diplomacy that aims at undermining the U.S.-led governance structures established after World War II" (Reisen 2015: 82). Thus, some commentators speculated that the establishment of the AIIB might lead to a "world of fragmented governance" (Subacchi 2015). In the Washington Post, Larry Summers wrote that " $[t]$ his past month may be remembered as the moment the US lost its role as the underwriter of the global economic system. . . I can think of no event since Bretton Woods comparable to the combination of China's effort to establish a major new institution and the failure of the US to persuade dozens of its traditional allies, starting with Britain, to stay out" (Summers 2015).

According to the 2019 White Paper on the Defense of Japan, China's regional rival interprets the creation of the AIIB as representing Beijing's attempt to create "its own international order." On an issue-area specific level, commentators feared that the establishment of the AIIB signifies the creation of an institutional structure that competes against the World Bank as the central institution of development finance (Subacchi 2015; The Economist 2014). More precisely, it was argued that the AIIB may serve to institutionalize a "Beijing Consensus," based on the norm of non-

\footnotetext{
${ }^{13}$ After having first ignored the discussions to create the AIIB, the US aimed at limiting the AIIB to a "minor regional bank with a small membership" (Chow 2016: 1275).

${ }^{14} \mathrm{https} / / / \mathrm{www}$.aiib.org/en/about-aiib/governance/members-of-bank/index.html
} 
interference with the internal affairs of countries, which competes against the "Washington Consensus," based on the norm of conditional lending (Chow 2016: 1263). The US in particular feared that the AIIB would be characterized by standards for environmental and social safeguards, transparency and accountability that diverge from those prevalent in the WB and, thus, reduce the joint gains realized through institutionalized cooperation in international development finance by reintroducing uncertainty about the behavior of lenders and borrowers alike (Desierto 2015). In other words, as Proposition 1 leads us to expect, the expectation was that diverging conditionalities across the two banks induce a race to the bottom in the standards of international development finance and, by implication, lessen behavioral adaptation by the borrowers to the preferences of the lenders and vice versa (Knoerich and Urdinez 2019: 357). In short, the expectation was that diverging conditionalities turn out to be detrimental to development.

However, in line with our theory and Proposition 2, the effects of the creation of the AIIB on international cooperation are anything but unequivocal. The very creation of the AIIB almost immediately triggered a process of inter-institutional accommodation between the two development banks. Thus, actually, only relatively few cooperation gains got lost, which is completely in line with our theory (see Section 4.2). To start with, China was only able to attract a global membership because it started to work towards inter-institutional accommodation with the WB early in the process of exercising CM (Rodrigues Vieira 2018; Wilson 2019). ${ }^{15}$ The members of the WB, in particular those with strong ties to the US, demanded a commitment to established norms and practices in multilateral development finance (Freeman 2019: 668, 670). In practice, they demanded that the AIIB is set up in a way that ensures at least basic complementarity with the WB and thus prevents large losses of cooperation gains due to a "race to the bottom" in the international standards of development finance. ${ }^{16}$

The ensuing process of inter-institutional accommodation manifested itself in two main ways. First, with the exception of the non-resident board of directors, the governance structure of the AIIB closely resembles the governance structure of the WB (Wilson 2019: 164). This is unsurprising because the AIIB used the WB mandate

\footnotetext{
${ }^{15}$ Initial members included "predominantly small, developing countries in South, Southeast and West Asia" (Wilson 2019: 160). Only inter-institutional accommodation enabled countries such as the UK, Germany, Italy, France, Switzerland, Australia, Korea, Brazil and Canada to join in at a later point. At this point, 4 of the G7 countries, 14 of the G20 countries, and 12 members of the European Union (EU) have joined the AIIB (Wilson 2019: 162). As a result, the membership of the AIIB includes all major world economies with the exceptions of the US and Japan.

${ }^{16}$ One may object that the desire to make the rules and procedures of the AIIB reasonably compatible with the WB significantly compromises the credibility of the signal that the challengers have sent to the defenders by creating the AIIB. Such an objection has merit. Our theoretical reasoning clearly implies that if the AIIB was designed in a way less compatible with the WB, the challengers would have signaled their resolve to contest the institutional status quo more strongly. That said, we maintain that setting up a completely new international institution still sends a credible signal of dissatisfaction and resolve when outright incompatibility is avoided. After all, China and its partners have shown that they are willing to invest the costs and to face the risks that are involved in creating a new international institution that enters the sphere of competence of an existing focal institution (see Section 3.2). In doing so, they have furthermore gained the ability to act independently of the defenders within an institutional framework which is, by and large, under their control. As a result, they are in a much better position to impose costs on the defenders of the institutional status quo than they were before the creation of the AIIB. Notwithstanding the fact that both banks are reasonably compatible at present, China and its partners could relatively easily reduce compatibility and use the AIIB to attack the WB, if this turns out to be conducive to their preferences in the future.
} 
as a template for its own regulatory framework (Lichtenstein 2018). ${ }^{17}$ Second, interinstitutional accommodation between the AIIB and the WB is institutionalized in Memoranda of Understanding. The AIIB has developed a formal partnership with the WB which includes agreements on co-financing, knowledge-sharing, technical cooperation, risk management, policy strategy and staff exchanges, among others (AIIB 2019; World Bank 2017; see also Freeman 2019: 668). As a result, the AIIB and the WB became able to co-finance projects efficiently. Since the AIIB started to operate in 2016, a "significant portion of the AIIB's projects" have been co-financed with the WB (Freeman 2019: 672). ${ }^{18}$ Within these arrangements, AIIB and WB agreed on joint supervision during project implementation with the WB being the lead supervisor (e.g. AIIB 2016). The AIIB, for its part, regards the WB loan conditions as "satisfactory" (AIIB 2017) and even "rel [ies] on the WB's determination of compliance with the [...] WB policies and procedures" (AIIB 2016: 5). Both development banks effectively ensure environmental and social standards as part of project implementations. In sum, not only does the AIIB's governance structure resemble that of the $\mathrm{WB}$, but also are its operations compatible, and executed jointly, with the WB. Thus, the inter-bank cooperation institutionalized in the Memoranda of Understanding arguably demands more inter-institutional adjustment from the AIIB than from the WB.

This case illustrates well the emergence of an institution-overarching governance arrangement that encompasses the two formerly rivaling institutions, as one of the two pathways to inter-institutional complementarity developed in Section 4.2. The exercise of CM through the creation of the AIIB by a group of states led by China started as a direct challenge to the WB, but resulted in a process of inter-institutional accommodation between the two institutions. During this process, China has adapted its behavior to the preferences of those members of the AIIB that are simultaneously members of the WB (Knoerich and Urdinez 2019). Likewise, then US President Barack Obama backtracked on earlier US hostilities toward the AIIB by saying 'let me be very clear and dispel this notion that we were opposed or are opposed to other countries participating in the [AIIB....We] look forward to collaborating with the [AIIB], just like we do with the [Asian Development Bank] and with the [WB]' (Obama 2015). Thus, also the US has adapted its behavior to the preferences of those members of the WB that are simultaneously members of the AIIB.

While it may be still relatively early to say, the AIIB seems to have become a "broad-based multilateral institution" with "transparent governance arrangements" that has adopted "policies consistent with international best practices for development financing" (Wilson 2019: 151). In many regards, it has transformed itself from a competitor with, to a collaborator of, the WB (Wilson 2019: 151). Against this backdrop, we acknowledge that the process of mutually complementary interinstitutional accommodation implies more accommodation on the part of the AIIB than on the part of the WB. While the central task of this case study has been to demonstrate that the evolving relationship between WB and AIIB has led to interinstitutional accommodation rather than to permanent competition or outright conflict,

\footnotetext{
${ }^{17}$ The AIIB mandate was established under the guidance of Natalie Lichtenstein, a former senior official at the WB. This is the most prominent example of China's approach to draw on the expertise of seasoned WB staff to hammer out and also to manage the AIIB (Yang 2016: 764).

${ }^{18}$ As of July 2019, 45\% of the investment operations approved by the AIIB have been prepared by it alone, whereas 55\% have been co-financed with other MDBs (Lichtenstein 2019: 584).
} 
an important task for future research is to study in greater detail the degree to which processes of mutually complementary institutional accommodation are (a) symmetrical across institutions.

\subsection{CM in the global governance of trade in GMOs: The WTO and the CBD}

Our second case - the governance of trade in GMOs - illustrates the potential of CM to be conducive to cooperation in a regulatory area, while exploring the second type of $\mathrm{CM}$, regime-shifting. At the center of the case is the conflict between diverging regulatory approaches pursued in the US and in the EU to regulate international trade in GMOs (Drezner 2007: Chapter 6): The US applies the principle of "substantial equivalence" which treats conventional and genetically modified products equally. The EU, by contrast, applies the precautionary principle which allows treating both types of products differently. The precautionary principle legitimizes the introduction of restrictive regulatory standards even if there is no sound scientific proof that GMOs are hazardous (Vogel 2003). Those regulatory standards are, however, perceived as nontariff barriers to trade by the focal institution of international trade, the WTO. According to WTO rules, international trade in GMOs may only be restricted if the hazardousness of a product is either proven by a sound scientific analysis or based on the standards of pertinent international institutions.

The regulation of international trade in GMOs therefore features a strong distributional conflict between the exporters of GMOs (led by the US) and their importers (led by the EU) (Drezner 2007: Chapter 6). Since the rules initially institutionalized within the WTO revolve around the principle of "substantial equivalence," the gains realized through cooperation in this focal institution were distributed unevenly among importers and exporters of GMOs (Pollack and Shaffer 2009: Chapter 4). Thus, GMO-importing countries became dissatisfied with the institutional status quo. However, institutional change in the focal WTO proved impossible.

In response to this stalemate, around the turn of the millennium, the importers decided to shift the process of institutional adjustment from the intra-institutional to the cross-institutional level by exercising "regime-shifting". More precisely, they moved their efforts to adjust the rules that govern trade in GMOs from the WTO to the CBD (Schneider and Urpelainen 2013). By deliberately creating "strategic inconsistency" with the pertinent WTO rules, the importers increased pressure on the exporters (Drezner 2005: 853-855). As expected, the GMO-exporting countries were opposed to these efforts and to adopting the so-called Cartagena Protocol on Biosafety, in particular to institutionalizing the precautionary principle within it (Graff 2002: 411). ${ }^{19}$ Thus, the US and Canada countered the "regime-shifting" of the GMOimporters by putting the regulation of international trade in GMOs on the agenda of the WTO Ministerial in Seattle. However, the negotiations within the WTO failed, because importing countries pointed to ongoing negotiations within the CBD framework (Falkner 2000: 305).

\footnotetext{
${ }^{19}$ The Cartagena Protocol aims to ensure the safe handling, transport and use of living modified organisms (LMOs) resulting from modern biotechnology that may have adverse effects on biological diversity, taking also into account risks to human health.
} 
The adoption of the Cartagena Protocol allowed the members of the CBD to restrict international trade in GMOs more strongly on the basis of legitimate interests in the protection from hazards than the pertinent WTO rules. ${ }^{20}$ Thus, by allowing GMOimporting countries to resort to precautionary measures, it serves as "a counterweight to the WTO SPS Agreement's narrower focus on science-based regulatory measures" (Pollack and Shaffer 2009: 156-157). As a result, states (in particular GMO-importers) gained greater leeway in determining their own regulatory rules.

In line with our Proposition 1, costs accrued to both sides. Regulating the relationship between the WTO and the Cartagena Protocol was subject to long and controversial negotiations which did not lead to a clear result. In essence, those negotiations failed because of the prevailing distributional conflict between importers (defending the rules of the Cartagena Protocol) and exporters (defending the WTO rules). As Drezner concludes, " $[\mathrm{t}]$ he result is a legal stalemate, with the Biosafety Protocol's precautionary principle flatly contradicting the trade regime's norm of scientific proof of harm" (Drezner 2005: 854).

This stalemate reduced the stability of states' expectations in regard to the regulation of international trade in GMOs. By implication, it reduced the realized joint gains (Pollack and Shaffer 2009: 117-119). The rivalry of both regulatory principles caused a fragmentation of the international markets for products that include GMOs. This fragmentation of markets, in turn, led to decreasing economies of scale, which contradicted the interests of exporting countries. At the same time, rivaling rules undermined the protection of consumers and the environment from the hazards emanating from GMOs. In sum, the exercise of CM by the GMO-importing countries turned out to be costly for both importers and exporters because it reduced the realized cooperation gains. Moreover, since the Cartagena Protocol created the need to navigate through a thicker, less organized and therefore more confusing web of institutionalized rules, it increased the transaction costs of regulating international trade in GMOs for importers and exporters alike. Thus, the exercise of CM by the GMO importers sent a credible signal of their resolve to contest the institutional status quo.

At the same time, in line with Proposition 2, both groups of actors developed an interest in mutually complementary institutional accommodation which would enable them to reap more cooperation gains than under continued "strategic inconsistency" (rivaling rules) between the WTO and the Cartagena Protocol. However, based on their diverging regulatory principles, both groups had diverging preferences in regard to how inter-institutional accommodation should be arranged. Thus, they found themselves in a "Battle of the Sexes" situation.

Given the sustained divergence of regulatory principles in the two groups of states, a process of mutually complementary institutional accommodation between the WTO and the Cartagena Protocol was triggered. The institutional adaptation of the Protocol to

\footnotetext{
${ }^{20}$ Article 10 (6) of the CBD stipulates that "Lack of scientific certainty due to insufficient relevant scientific information and knowledge regarding the extent of the potential adverse effects of a living modified organism on the conservation and sustainable use of biological diversity in the Party of import, taking also into account risks to human health, shall not prevent that Party from taking a decision, as appropriate, with regard to the import of the living modified organism in question as referred to in paragraph 3 above, in order to avoid or minimize such potential adverse effects." And Article 11(8) adds that "[...] a lack of scientific certainty shall not prevent a party from taking measures to avoid or minimize potential adverse effects of GMOs to be imported as food or feed."
} 
the pertinent WTO-rules is reflected, first, in the attempt to make the rules of the Protocol as compatible with the WTO as possible, the "strategic inconsistency" between the two regulatory approaches notwithstanding. The design of the Protocol reflects the "chill effect" which implies that, given that the WTO enjoyed a "first mover advantage" on regulating trade in GMOs, the Cartagena Protocol, as the second mover, was designed by its members to at least partially prevent outright contradiction (Eckersley 2004). Moreover, institutional adaptation is reflected in the restricted area of application of the Protocol's central regulatory instrument - the Advance Informed Agreement (AIA) - which implies that the Protocol does not apply to a considerable part of trade in GMOs (Eggers and Mackenzie 2000: 526).

On the side of the WTO, the search for complementarity proved more problematic, as the deadlock in the Doha Round made it impossible for the WTO to react to the creation of the Cartagena Protocol through its legislative body. However, the institutional adaptation of the WTO to the Cartagena Protocol could be pursued by its judicial body. In the Biotech case between the EU and the US, the WTO's Dispute Settlement Mechanism decided that every country can decide independently how stringently it regulates its own market (World Trade Organization 2006). This decision responds to the claim put forward by three GMO-exporting countries (the US, Canada and Argentina) that the restrictive regulations of the EU are incompatible with WTO law (Lieberman and Gray 2008: 38-40). It emphasizes that pertinent WTO rules provide a basis to put in place precautionary measures even when risk assessment has not reached a conclusive or unequivocal result (Krisch 2010: 196). The decision repeatedly takes up the consequences of scientific uncertainty and accepts that GMO-importing states may take scientific risk assessment into account (World Trade Organization 2006: 7.3044).

This decision clearly diverges from previous decisions which rejected the precautionary principle (Schneider and Urpelainen 2013). Over an extended period of time, the WTO Dispute Settlement Mechanism had consistently decided that environmentally motivated trade restrictions - such as those enshrined in the Cartagena Protocol contradict the central principles on which the liberal trade order is built (Schoenbaum 2002: 701-703). This strongly suggests that the novel decision adopted in the Biotech case indeed responds to the "strategic inconsistency" created when GMO-importing countries shifted their regulatory efforts to the CBD. In line with our Proposition 2, it adapts the WTO to the "strategic inconsistency" created by the Cartagena Protocol and thus contributes to mutually complementary inter-institutional accommodation. In combination with the limitations of the Protocol's applicability mentioned above, the steps by the WTO lead to a de facto split of the area of overlap between the two institutions. The accommodation process by the two institutions thus represents an example of the second type of inter-institutional complementarity where the bodies seek to demarcate their spheres of applicability, limiting the amount of direct overlap and regulatory rivalry (see Section 4.2$).^{21}$

\footnotetext{
${ }^{21}$ We acknowledge that the process of institutional accommodation within the WTO has been carried out not only by the member states (that is, by the defenders of the institutional status quo), but also by an institutional agent to which member states have delegated decision-making power (the WTO DSB). Though not explicitly theorized, we expect that such an institutional agent adopts its decisions in a way that, at a minimum, does not clearly violate the preferences of the defenders (and of the of wider membership). To study much more thoroughly how institutional agents contribute to inter-institutional accommodation is an important task for future research (see Conclusion).
} 
In sum, the outlined process of mutually complementary institutional accommodation considerably reduced the behavioral uncertainty that characterized the regulation of international trade in GMOs after the creation of the Cartagena Protocol. It therefore increased the joint gains that states can reap through institutionalized cooperation.

\section{Conclusion}

The two case studies presented above corroborate two key theoretical claims: First, CM not only represents a reaction by the challengers of a given institutional status quo to deadlocked institutional adjustment bargaining, but also sends a credible signal of their resolve to contest it. Inherent in this signal is the potential to overcome deadlock by changing the dynamics of institutional adjustment bargaining. Second, "strategic inconsistency," that is, the rivaling rules created by CM, may give rise to a process of inter-institutional accommodation which results in inter-institutional complementarity. By that, CM may re-create lost cooperation gains. Although the two case studies do not allow us to answer more fine-grained questions on processes of inter-institutional accommodation, such as whether each of the two institutions accommodates equally to the other, they clearly demonstrate that, in both cases, the exercise of CM led neither to outright conflict, nor to lasting competition between the institutions, but induced inter-institutional complementarity.

Our findings suggest that if challengers (e.g. rising powers) choose to engage in CM, they may very well gain from it, if inter-institutional complementarity is reached. At the same time, defenders (e.g. established powers) are likely to minimize their losses if they do not resist adjustments of the incumbent focal institutions. And if institutional adjustment bargaining indeed fails and CM takes place, it is important that the defenders (e.g. the established powers) engage pragmatically in the processes seeking inter-institutional complementarity to regain most of the lost gains. The worst-case scenario is a permanent lock-in with conflicting sets of provisions and sizable losses of cooperation gains for both parties.

A set of scope conditions needs to be met for our theoretical reasoning to apply. While these scope conditions were directly built into the analysis above, we provide a summary here: First, the gains that are realized through cooperation in an existing focal institution have to be distributed unevenly among two groups of states; second, the two groups of states must be able to act collectively vis-à-vis each other which presupposes that interests converge more strongly within the two groups than across them; third, the two groups need to be similarly powerful, so that none can impose its preferences on the other; fourth, the deadlock in institutional adjustment bargaining that gives rise to the exercise of CM must result from challengers' inability to credibly communicate the degree to which they are resolved to challenge defenders over the institutional status quo; and fifth, after the exercise of CM both groups must be willing to offer reciprocal concessions via 'their' institutions in order to re-create cooperation gains.

Admittedly, these scope conditions are demanding and suggest that, at present, our theoretical argument does not apply to a large number of empirical cases. However, the contemporary shift in the global distribution of power leads us to expect that the empirical importance of our theoretical argument is bound to grow significantly in the years and decades to come. Apart from that, we may expect that successful 
examples of CM, like the ones studied above, will gradually incentivize more groups of dissatisfied states to resort to it in the future. Thus, a more rigorous empirical testing of our theoretical reasoning, which draws on a larger number of cases, is an important task for future research on "cooperation in a thickly institutionalized international system." The two plausibility probes presented above suggest that such testing is warranted.

Future research should also explore how simplifying assumptions included in our modelling impact the effects of CM on international cooperation. ${ }^{22}$ Two assumptions appear most prominent, and promising for further inquiry: First, in our model we assume that the distribution of power between challengers and defenders is symmetrical and stable over time. It is, however, conceivable that the distribution of power between challengers and defenders (especially between rising and established powers) changes over time. Future research should therefore study how dynamic changes in the distribution of power between challengers and defenders affects the effect of CM on the realization of cooperation gains. We may expect that a changing distribution of power makes the interaction between challengers and defenders more difficult. As a result, the prospect of reaching inter-institutional complementarity through mutually complementary institutional adaptation becomes less likely. Second, we assume that both challengers and defenders are internally cohesive groups. It is, however, possible to envision more complex models of CM which are built on the assumption of partial incoherence within the two groups. We may expect partial incoherence, for example, when more than two major powers are involved in the strategic interaction between challengers and defenders or when a major power in one group incentivizes less powerful states that belong to the other group not to support the major power which leads their group. Again, we may expect that reduced internal cohesiveness makes the interaction between the two groups more difficult. By implication, the prospect of reaching inter-institutional complementarity becomes less likely.

We also expect that relaxing each of the two simplifying assumptions makes it less likely that CM is exercised in the first place. As we establish in Section 3.2, the exercise of $\mathrm{CM}$ is a costly and risky endeavor which presupposes the ability to act collectively on the part of the defenders. Reduced internal cohesiveness among the challengers, however, reduces their ability to act collectively and, thus, to exercise CM. Likewise, a more asymmetrical distribution of power in favor of the defenders disincentivizes the challengers from resorting to $\mathrm{CM}$ given that the risks and costs associated with its exercise are comparatively unlikely to pay off.

Lastly, future research should analyze the contributions institutional agents (e.g. dispute settlement bodies) can make to processes of inter-institutional accommodation. Given that international institutions are replete with veto players who can prevent or stop processes of inter-institutional accommodation (a fact that contributes to inhibiting this process from becoming more widespread), institutional agents can be particularly conducive to recreating cooperation gains lost through the exercise of CM (see Section 5.2). In summary, the phenomenon of $\mathrm{CM}$ and its effects on patterns of international cooperation represents a broad and promising agenda for important future research on international institutions.

\footnotetext{
${ }^{22}$ We should emphasize, however, that neither perfect internal group coherence, nor complete power symmetry between the groups are needed for our key insight concerning the collective and individual costs from CM, formulated in Proposition 1, to hold.
} 
Acknowledgements Michal Parizek gratefully acknowledges financial support from the Peace Research Center Prague, Charles University, project UNCE/HUM/028. Previous versions of this paper were presented at several academic conferences and workshops. The input of all participants in these meetings is gratefully acknowledged. We are particularly indebted to Tobias Berger, Alejandro Esguerra, Robert O. Keohane, Jean Pisani-Ferry, Krzysztof Pelc, Christian Rauh, Thomas Rixen, Theresa Squatrito, Alexandros Tokhi and Catherine Weaver. We would also like to thank three anonymous reviewers for their constructive comments that greatly improved the paper.

Open Access This article is licensed under a Creative Commons Attribution 4.0 International License, which permits use, sharing, adaptation, distribution and reproduction in any medium or format, as long as you give appropriate credit to the original author(s) and the source, provide a link to the Creative Commons licence, and indicate if changes were made. The images or other third party material in this article are included in the article's Creative Commons licence, unless indicated otherwise in a credit line to the material. If material is not included in the article's Creative Commons licence and your intended use is not permitted by statutory regulation or exceeds the permitted use, you will need to obtain permission directly from the copyright holder. To view a copy of this licence, visit http://creativecommons.org/licenses/by/4.0/.

\section{References}

AIIB. (2016). Project document of AIIB. Islamic Republic of Pakistan, Tarbela 5 hydropower extension project. Asian Infrastructure Investment Bank.

AIIB. (2017). Project document of AIIB. Regional infrastructure development fund project, Republic of Indonesia. Asian Infrastructure Investment Bank.

AIIB. (2019). AIIB signs agreements to deepen international cooperation. AIIB News. https://www.aiib. org/en/news-events/news/2019/AIIB-Signs-Agreements-to-Deepen-International-Cooperation.html

Alter, K. J., \& Meunier, S. (2009). The politics of international regime complexity. Perspectives on Politics, 7(1), 13-24. https://doi.org/10.1017/S1537592709090033.

Alter, K. J., \& Raustiala, K. (2018). The rise of international regime complexity. Annual Review of Law and Social Science, 14(1), 329-349. https://doi.org/10.1146/annurev-lawsocsci-101317-030830.

Andornino, G. B. (2019). Economic-security Nexus in the AIIB: China's quest for security through Eurasian connectivity. Global Policy, 10(4), 604-613. https://doi.org/10.1111/1758-5899.12762.

Axelrod, R. (1981). The emergence of cooperation among egoists. The American Political Science Review, 75(2), 306-318. https://doi.org/10.2307/1961366.

Axelrod, R., \& Keohane, R. O. (1985). Achieving cooperation under anarchy: Strategies and institutions. World Politics, 38(1), 226-254. https://doi.org/10.2307/2010357.

Busch, M. L. (2007). Overlapping institutions, forum shopping, and dispute settlement in international trade. International Organization, 61(04), 735-761. https://doi.org/10.1017/S0020818307070257.

Chow, D. C. K. (2016). Why China established the Asian infrastructure investment Bank. Vanderbilt Journal of Transnational Law, 4, 1255-1298.

Desierto, D. (2015). Breaking the Washington consensus? The rise of 'alternative' development banks. EJIL: Talk! https:/www.ejiltalk.org/breaking-the-washington-consensus-the-rise-of-alternative-developmentbanks/. Accessed 25 May 2020.

Drezner, D. W. (2005). Globalization, harmonization, and competition: The different pathways to policy convergence. Journal of European Public Policy, 12(5), 841-859. /https://doi.org/10.1080 $/ 13501760500161472$.

Drezner, D. W. (2007). All politics is global: Explaining international regulatory regimes. Princeton University Press.

Drezner, D. W. (2013). The tragedy of the global institutional commons. In M. Finnemore \& J. Goldstein (Eds.), Back to basics: State power in a contemporary world (pp. 280-310). New York: Oxford University Press. https://doi.org/10.1093/acprof:oso/9780199970087.003.0013 .

Eckersley, R. (2004). The big chill: The WTO and multilateral environmental agreements. Global Environmental Politics, 4(2), 24-50. https://doi.org/10.1162/152638004323074183.

Eckstein, H. (1975). Case study and theory in political science. In F. I. Greenstein \& N. W. Polsby (Eds.), Handbook of Political Science, Vol. 7 (pp. 79-138). Reading: Addison-Wesley. /https://doi.org/10.4135 /9780857024367.d11. 
Eggers, B., \& Mackenzie, R. (2000). The Cartagena protocol on biosafety. Journal of International Economic Law, 3(3), 525-543. https://doi.org/10.1093/jiel/3.3.525.

Falkner, R. (2000). Regulating biotech trade: The Cartagena protocol on biosafety. International Affairs, 76(2), 299-313.

Fearon, J. D. (1995). Rationalist explanations for war. International Organization, 49(3), 379-414.

Fearon, J. D. (1998). Bargaining, enforcement, and international cooperation. International Organization, 52(2), 269-305. https://doi.org/10.1162/002081898753162820.

Freeman, C. P. (2019). Constructive engagement? The US and the AIIB. Global Policy, 10(4), 667-676. https://doi.org/10.1111/1758-5899.12764.

Gehring, T., \& Faude, B. (2014). A theory of emerging order within institutional complexes: How competition among regulatory international institutions leads to institutional adaptation and division of labor. The Review of International Organizations, 9(4), 471-498. https://oi.org/10.1007/s11558-014-9197-1.

Gehring, T., \& Oberthür, S. (2009). The causal mechanisms of interaction between international institutions. European Journal of International Relations, 15(1), 125-156. https://doi.org/10.1177/1354066108100055.

George, A. L., \& Bennett, A. (2005). Case studies and theory development in in the social sciences. Cambridge: MIT Press.

Gillespie, A. (2002). Forum shopping in international environmental law: The IWC, CITES, and the Management of Cetaceans. Ocean Development and International Law, 33(1), 17-56.

Graff, L. (2002). The precautionary principle. In C. bail, R. Falkner, \& H. Marquard (Eds.), The Cartagena Protocol on Biosafety: Reconciling Trade in Biotechnology with Environment and Development? (pp. 410-422). London, Washington, D.C: Routledge.

Gutner, T. (2019). Critical junctures, strategic choice, and the birth of the AIIB. Paper presented at ECPR Joint Sessions, Mons, April 8-12, 2019.

Helfer, L. R. (2009). Regime shifting in the international intellectual property system. Perspectives on Politics, 7(1), 39-44. https://doi.org/10.1017/S1537592709090069.

Hinich, M. J., \& Munger, M. C. (1997). Analytical politics. Cambridge: Cambridge University Press.

Hirschman, A. O. (1970). Exit, voice, and loyalty: Responses to decline in firms, organizations, and states. Boston: Harvard University Press.

Hopewell, K. (2015). Different paths to power: The rise of Brazil, India and China at the World Trade Organization. Review of International Political Economy, 22(2), 311-338. /https://doi.org/10.1080 /09692290.2014.927387.

Jupille, J., Mattli, W., \& Snidal, D. (2013). Institutional choice and global commerce. Cambridge: Cambridge University Press.

Keohane, R. O. (1984). After hegemony: Cooperation and discord in the world political economy. Princeton: Princeton University Press.

Knoerich, J., \& Urdinez, F. (2019). Contesting contested multilateralism: Why the west joined the rest in founding the Asian infrastructure investment Bank. The Chinese Journal of International Politics, 12(3), 333-370. /https://doi.org/10.1093/cjip/poz007.

Krasner, S. D. (1991). Global communications and National Power: Life on the Pareto frontier. World Politics, 43(3), 336-366. /https://doi.org/10.2307/2010398.

Krisch, N. (2010). Beyond constitutionalism: The pluralist structure of Postnational law. Oxford: Oxford University Press. https://www.oxfordscholarship.com/view/10.1093 /acprof:oso/9780199228317.001.0001/acprof-9780199228317. Accessed 25 May 2020.

Lake, D. A. (2009). Hierarchy in international relations. Ithaca: Cornell University Press.

Lax, D. A., \& Sebenius, J. K. (1986). The manager as negotiator: Bargaining for cooperation and competitive gain. New York: Free Press.

Lichtenstein, N. (2018). A comparative guide to the Asian infrastructure investment Bank. Oxford: Oxford University Press.

Lichtenstein, N. (2019). AIIB at three: A comparative and institutional perspective. Global. Policy, 10(4), 582-586. https://doi.org/10.1111/1758-5899.12703.

Lieberman, S., \& Gray, T. (2008). The World Trade Organization's report on the EU's moratorium on biotech products: The wisdom of the US challenge to the EU in the WTO. Global Environmental Politics, 8(1), 33-52. /https://doi.org/10.1162/glep.2008.8.1.33.

Lipscy, P. Y. (2017). Renegotiating the world order: Institutional change in international relations. Cambridge: Cambridge University Press.

Mackintosh, S. P. M. (2016). The creation of the Asian infrastructure and investment Bank: America's loss and China's gain. World Economics, 17(3), 25-38.

Morrow, J. D. (1994). Modeling the forms of international cooperation: Distribution versus information. International Organization, 48(3), 387-423. 
Morrow, J. D. (1999). The strategic setting of choices: Signaling, commitment, and negotiation in international politics. In D. A. Lake \& R. Powell (Eds.), Strategic choice and international relations (pp. 77-114). Princeton: Princeton Univ Press.

Morse, J. C., \& Keohane, R. O. (2014). Contested multilateralism. The Review of International Organizations, 9(4), 385-412. /https://doi.org/10.1007/s11558-014-9188-2.

Narlikar, A., \& Van Houten, P. (2010). Know the enemy: Uncertainty and deadlock in the WTO. In A. Narlikar (Ed.), Deadlocks in multilateral negotiations: Causes and solutions (pp. 142-163). Cambridge: Cambridge University Press.

Obama, B. (2015). Remarks by President Obama and Prime Minister Abe of Japan in Joint Press Conference. (28 April) available at: <https://obamawhitehouse.archives.gov/thepress-office/2015/04/28/remarkspresident-obama-and-prime-minister-abe-japan-jointpress-confere $>$.

Oye, K. A. (Ed.) (1986). Cooperation under anarchy. Princeton: Princeton University Press.

Pierson, P. (2004). Politics in time: History, institutions, and social analysis. Princeton: Princeton University Press.

Pollack, M., \& Shaffer, G. C. (2009). When cooperation fails: The international law and politics of genetically modified foods. New York: Oxford University Press.

Raustiala, K., \& Victor, D. G. (2004). The regime complex for plant genetic resources. International Organization, 58(02), 277-309. /https://doi.org/10.1017/S0020818304582036.

Reisen, H. (2015). Alternative multilateral development banks and global financial governance. International Organisations Research Journal, 10(2), 106-118.

Rodrigues Vieira, V. (2018). Who joins counter-hegemonic IGOs? Early and late members of the China-led Asian infrastructure investment Bank. Research \& Politics, 5(2), 2053168018770031. /https://doi. org/10.1177/2053168018770031.

Schneider, C. J., \& Urpelainen, J. (2013). Distributional conflict between powerful states and international treaty ratification. International Studies Quarterly, 57(1), 13-27. /https://doi.org/10.1111/isqu.12024.

Schoenbaum, T. J. (2002). International trade and environmental protection. In P. Birnie \& A. B. Boyle (Eds.), International law and the environment (pp. 697-750). Oxford: Oxford University Press.

Snidal, D. (1985). The limits of hegemonic stability theory. International Organization, 39(04), 579-614. /https://doi.org/10.1017/S002081830002703X.

Subacchi, P. (2015). The AIIB is a threat to global economic governance. Foreign Policy https://foreignpolicy. com/2015/03/31/the-aiib-is-a-threat-to-global-economic-governance-china/. Accessed 25 May 2020.

Summers, L. (2015). A global wake-up call for the US? Washington Post.

The Economist. (2014). Why China is creating a new "World Bank" for Asia. https://www.economist. com/the-economist-explains/2014/11/11/why-china-is-creating-a-new-world-bank-for-asia. Accessed 25 May 2020.

Urpelainen, J., \& Van de Graaf, T. (2014). Your place or mine? Institutional capture and the creation of overlapping international institutions. British Journal of Political Science, FirstView, 1-29. /https://doi. org/10.1017/S0007123413000537.

Vestergaard, J., \& Wade, R. H. (2015). Still in the woods: Gridlock in the IMF and the World Bank puts multilateralism at risk. Global Policy, 6(1), 1-12. /10.1111/1758-5899.12178.

Van de Graaf, T. (2013). Fragmentation in global energy governance: Explaining the creation of IRENA. Global Environmental Politics, 13(3), 14-33.

Vogel, D. (2003). The hare and the tortoise revisited: The new politics of consumer and environmental regulation in Europe. British Journal of Political Science, 33(4), 557-580.

Wilson, J. (2019). The evolution of China's Asian infrastructure investment Bank: From a revisionist to statusseeking agenda. International Relations of the Asia-Pacific, 19(1), 147-176.

World Bank. (2017). World Bank and AIIB Sign Cooperation Framework. https://www.worldbank. org/en/news/press-release/2017/04/23/world-bank-and-aiib-sign-cooperation-framework

World Trade Organization. (2006). DS291: European Communities - Measures Affecting the Approval and Marketing of Biotech Products. https:/www.wto.org/english/tratop_e/dispu_e/cases_e/ds291_e.htm

Yang, H. (2016). The Asian infrastructure investment Bank and status-seeking: China's foray into global economic governance. Chinese Political Science Review, 1(4), 754-778. https://doi.org/10.1007/s41111016-0043-X.

Zangl, B., Heußner, F., Kruck, A., \& Lanzendörfer, X. (2016). Imperfect adaptation: How the WTO and the IMF adjust to shifting power distributions among their members. The Review of International Organizations, 11(2), 171-196. https://doi.org/10.1007/s11558-016-9246-z.

Publisher's note Springer Nature remains neutral with regard to jurisdictional claims in published maps and institutional affiliations. 